\title{
CLINICAL AND MICROBIOLOGICAL FEATURES OF EARLY-ONSET NEONATAL SEPSIS IN PRETERM INFANTS
}

\author{
Tetiana Klymenko \\ klimenko57.t@gmail.com \\ Kateryna Kosenko ${ }^{1}$ \\ kosenko.kateryna16@gmail.com \\ ${ }^{1}$ Neonatology Department \\ Kharkiv Medical Academy of Postgraduate Education \\ 58 Amosova str., Kharkiv, Ukraine, 61176
}

\begin{abstract}
Early-onset neonatal sepsis (EONS) remains the leading cause of morbidity and mortality, especially among premature infants. Conducting high-quality epidemiological monitoring is an important condition for effective tactics treatment neonatal infections and improving the quality of medical care for this category of newborn.

The aim. Determination of the value of microbiological triggers in the blood in various clinical options for EONS in preterm infants.

Materials and methods. Clinical and microbiological data on 50 prematurely born newborns with EONS were selected. The analysis of the frequency of detected bacteremia, the distribution of pathogenic microorganisms and the clinical characteristics of neonatal sepsis.

Results. In the study, sources of infection were detected in $94 \%$ of cases. Positive blood cultures were obtained in 17 (34 \%) newborns with EONS. $61.5 \%$ of all cases of bacteremia were caused by coagulase-negative staphylococcus (CoNS). Gram-negative pathogens were detected in $23.5 \%$ of positive blood cultures, representatives of this group were Escherichia coli and Klebsiella pneumonia. The overall mortality rate from EONS was $30 \%$.

Conclusions. The incidence of sepsis confirmed by a positive blood culture was $34 \%$. The most common cause of EONS is CoNS, low incidence of group B Streptococcus sepsis has been established. The most frequent septicopymic sources of infection were the lungs, which is expressed in the high incidence (94\%) of X-ray pneumonia in the structure of the EONS.
\end{abstract}

Keywords: early-onset neonatal sepsis, epidemiology, preterm infants.

DOI: $10.21303 / 2504-5679.2020 .001284$

\section{Introduction}

Despite measures to improve the quality of care for newborns, neonatal sepsis (NS) is the cause of significant morbidity and mortality [1, 2]. Compared to full-term infants, NS is more common in premature babies and is associated with a higher mortality rate and the further development of long-term adverse effects, including severe disabling lesions of the central nervous system $[3,4]$.

Depending on the time of implementation of the clinical manifestations, it is customary to distinguish between early neonatal sepsis (EONS) and late onset neonatal sepsis (LONS). EONS develops in the first 72 hours after birth, usually due to transplacental or ascending infection [5].

The frequency of culture-proven EONS in the USA is 0.77 per 1000 live births, in Norway 0.54 per 1000 live births $[6,7]$. The frequency of EONS in Australia is 0.69 per 1000 newborns, and in Switzerland -0.28 per 1000 live births $[8,9]$.

In more than $85 \%$ of infants, EONS symptoms appear in the first 24 hours of life, in $5 \%$ within 24-48 hours after birth, in a small number of newborns, the disease is diagnosed in the interval from 48 to 72 hours of life [10].

The non-specificity of clinical symptoms and the insufficient diagnostic value of existing laboratory tests lead to defects in the registry and monitoring of this disease, the inability to conduct an unambiguous assessment of the existing epidemiological and microbiological 
situation in various health systems and the subsequent effective implementation of preventive measures [11].

Sterile bacterial culture is the "gold" standard for the diagnosis of NS, however, blood cultures have certain limitations. It should be noted that the inability to isolate the microbial pathogen in the blood of a newborn child does not exclude the diagnosis of sepsis [12].

Pathogens that cause EONS and their susceptibility to antibiotics have significant differences in different countries [13]. Therefore, conducting epidemiological monitoring of neonatal infections is an important condition for ensuring timely, effective therapeutic policies within a single intensive care unit, hospital, and public health system.

The aim of the study. Determination of the value of microbiological triggers in the blood in various clinical options for early neonatal sepsis in premature infants.

\section{Materials and methods}

The study was conducted from 2016 to 2019 on the base of Kharkiv city perinatal center. An analysis of 50 cases of EONS in prematurely born infants at 24 to 36 weeks of gestation was performed. A detailed description of the patients is given in Table $\mathbf{1}$.

Table 1

Patient Characterization

\begin{tabular}{ccc}
\hline Characteristic & $\mathbf{n}$ & \% \\
\hline Male & Gender & 54 \\
Female & 27 & 46 \\
\hline & 23 & 48 \\
\hline 28 & Gestational age (weeks) & 28 \\
$28-32$ & 24 & 24 \\
\hline $33-36$ & 14 & 40 \\
& 12 & 26 \\
$1000-1499$ & Birth weight (grams) & 18
\end{tabular}

The diagnosis of EONS was made according to the standards of management of newborns with suspected early neonatal guidance for management of Early Onset Sepsis NICE (National Institute of Clinical Excellence) infection. In addition to assessing the clinical picture of the disease, laboratory studies were carried out, including counting the number of leukocytes (white blood cells $>15$ or $<5 \cdot 10^{9} / 1$ ), the ratio of immature to the total number of neutrophils (ratio I:T $>0.3$ ), the concentration of C-reactive protein (diagnostic value in venous blood $>10 \mathrm{mg} / \mathrm{l}$ ), procalcitonin (diagnostic value in venous blood $>2 \mathrm{ng} / \mathrm{ml}$ ).

Venous blood for cultures and laboratory tests (mainly WBC, C-reactive protein, and procalcitonin) was obtained at the onset of clinical symptoms of infection before antibiotic therapy. Other studies have been clinically indicated and included chest or abdominal radiography, microscopy and culture of cerebrospinal fluid, and tracheal aspiration culture. The protocol of the study was in accordance with the Council of Europe Convention on Human Rights and Biomedicine, the Helsinki Declaration of the World. 
Statistical analysis was performed using the software package Microsoft Office Excel and Statistica. Nominal data were described with absolute values and percentages. According to the expected and observed frequency Fisher's exact test was used for contingency tables. Results associated with $\mathrm{p}$-values $<0.05$ were considered statistically significant. Data were analyzed using phi correlation coefficient.

\section{Results}

Among the newborns examined, 38 children (76\%) were born $<32$ weeks of gestation, which of $20(40 \%)$ were born with extremely low body weight.

Source of infection were identified in $94 \%$ of cases (Table 2). In most cases, the septicopyemic source of infection were lungs with an X-ray picture of pneumonia. In 3 children $(6 \%)$, the disease proceeded against an isolated septicemia without identifying a septicopyemia focus.

Table 2

Clinical forms of early onset neonatal sepsis in premature babies

\begin{tabular}{lcc}
\hline \multicolumn{1}{c}{ Clinical course } & $\mathbf{n}$ & (\%) \\
\hline Septicemia & 3 & 6 \\
Septicemia + Pneumonia & 13 & 26 \\
Septicemia + Meningoencephalitis + Pneumonia & 1 & 2 \\
Pneumonia* & 13 & 26 \\
Meningoencephalitis + Pneumonia & 5 & 10 \\
Pneumonia + NEC & 8 & 16 \\
Meningoencephalitis + Pneumonia + UTI & 1 & 2 \\
Pneumonia + UTI & 4 & 8 \\
Pneumonia + Omphalitis & 2 & 4 \\
Total & 50 & 100
\end{tabular}

Note: * - pneumonia in newborns with clinical signs of sepsis with laboratory data of a systemic inflammatory response syndrome and multiple organ failure and/or shock, NEC-necrotizing enterocolitis, UTI-urinary tract infection

In the study, positive blood cultures were obtained in 17 (34\%) newborns with EONS. The main microbial agents were representatives of gram-positive cocci group.

Coagulase-negative staphylococcus (CoNS) was the most common pathogen, it accounted for $61.5 \%$ of all cases of bacteremia.

Gram-negative pathogens were detected in $23.5 \%$ of positive blood cultures, representatives of this group were Escherichia coli and Klebsiella pneumonia. It should be noted that not a single isolate of fungal flora was found.

The structures of bacterial pathogens isolated in the blood are presented in detail in Table 3.

The mortality rate from EONS was $30 \%$. In the group of deceased newborns, severe hypoxic-hemorrhagic lesions of the central nervous system, the development of septic shock and multiple organ failure was observed (Table 4). The phi-square revealed a significant relationship between IVH 3 stage, septic shock, MODS and outcome of sepsis. Necrotizing enterocolitis (NEC), meningoencephalitis, urinary tract infection did not significantly affect the outcome of sepsis. This was also confirmed by the presence of a significant relationship in the interpretation of the Phi coefficient.

In children with positive blood cultures $(n=17), 4$ deaths were noted, which in $100 \%$ of cases were due to gram-positive pathogens. 
Table 3

Characterization of microbial pathogens of early neonatal sepsis in premature infants with positive blood culture

\begin{tabular}{ccc}
\hline Pathogen & $\mathbf{n}$ & (\%) \\
\hline Gram-positive bacteria & 13 & 76.5 \\
Staphylococcus coagulase negative & 8 & 47 \\
Listeria monocytogenes & 2 & 11.8 \\
Group B Streptococcus & 1 & 5.8 \\
Staphylococcus aureus & 2 & 11.8 \\
Gram-negative bacteria & 4 & 23.5 \\
Escherichia coli & 2 & 11.8 \\
Klebsiella pneumoniae & 2 & 11.8 \\
Total amount & 17 & 100
\end{tabular}

Table 4

EONS mortality predictors in premature babies

\begin{tabular}{ccccccc}
\hline & $\begin{array}{c}\text { Non- survival } \\
\mathbf{n = 1 5}\end{array}$ & $\begin{array}{c}\text { Survival } \\
\mathbf{n = 3 5}\end{array}$ & $\begin{array}{c}\text { Fisher's } \\
\text { exact test }\end{array}$ & $\mathbf{p}$ & $\boldsymbol{\varphi}$ & $\begin{array}{c}\text { Interpretation of } \\
\text { the Phi coefficient }\end{array}$ \\
\hline NEC & 3 & 5 & 0.68255 & $>0,05$ & 0.071 & negligible positive relationship \\
IVH 3 stage & 8 & 2 & 0.00039 & $<0,05$ & 0.546 & substantial positive relationship \\
Meningoencephalitis & 3 & 4 & 0.41499 & $>0,05$ & 0.113 & low positive relationship \\
UTI & 3 & 2 & 0.15174 & $>0,05$ & 0.218 & low positive relationship \\
Septic shock & 7 & 2 & 0.00162 & $<0,05$ & 0.488 & moderate positive relationship \\
MODS & 11 & 4 & 0.00003 & $<0,05$ & 0.619 & substantial positive relationship
\end{tabular}

Note: NEC - necrotizing enterocolitis, IVH - intraventricular hemorrhage, UTI - urinary tract infection, MODS - multiple organ failure syndrome, $p$ - confidence level, $\varphi$ - Phi coefficient

\section{Discussion}

Despite the actively ongoing search for new markers, blood culture is still recognized as the gold standard for the diagnosis of NS [14]. In our study, the incidence of positive blood culture in preterm infants with EONS was $34 \%$. The low level of bacteremia, as well as the insufficient volume taken for blood tests, especially in children with extremely low body weight, may be one of the explanations for a large number of cases of culture-negative sepsis. In addition, antibiotic treatment in the mother before or during childbirth may in some cases mask the detection of bacteremia in the newborn [15]. In cases where the blood cultures and other sterile cultures are negative, but the child shows signs that correspond to the implementation of the infectious process, they can be considered "clinical" sepsis [16].

Most publications on neonatal sepsis management from high-income countries include only culturally confirmed cases. A large number of newborns who received antibiotics for the treatment of sepsis with a negative result of seeding in epidemiological studies are largely ignored.

Reliable epidemiological data on culture-negative sepsis are limited [17]. Moreover, according to recent studies, it is known that the number of children receiving systemic antibiotic therapy in culture-negative sepsis exceeds the number of children receiving therapy with bacteriologically-confirmed sepsis. 
The ratio of culture-confirmed and culture-negative cases of sepsis in Canada is 1:7, and in Norway the indicator reaches 1:16 [18, 19]. In the SCOUT study, researchers evaluated antibiotic intake for various conditions in 2,500 full-term and premature infants. Culture-confirmed infection and NEC accounted for only $6.9 \%$ of antibiotic use [20]. At the same time, it was proved that prolonged antimicrobial therapy in children with negative blood cultures, without proven infection, increases the risk of mortality, bronchopulmonary dysplasia, NEC, retinopathy and damage to the white matter in the periventricular region, and also leads to the appearance of multi-resistant strains of microorganisms $[21,22]$. On the other hand, delayed antibiotic therapy in truly infected newborns can lead to increased mortality and morbidity [23]. Thus, culture-negative NS is at the crossroads between effective sepsis treatment programs and antimicrobial programs.

In the study, the structure of pathogens was dominated by representatives of gram-positive bacteria, mainly CoNS (47\%). The study of the world microbiological landscape demonstrates a significant heterogeneity of the distribution of pathogens in the structure of the EONS.

So in the British and French studies, the dominant etiological factor in the development of EONS is GBS (43\% and $58.5 \%$, respectively) [24, 25]. In a Swedish study, EONS was triggered by group B Streptococcus at a significantly lower percentage $(20 \%)$, with CoNS accounting for $30 \%$ [26]. The situation was different in South Korea and Denmark, where the main causative agent of EONS was S. aureus (48\% and $36 \%$ ) [27, 28]. Mexico and Turkey dominated CoNS with a prevalence of $55.5 \%$ and $60.9 \%$, respectively, which is consistent with our research $[29,30]$.

Gram-negative bacteria in our study accounted for $23.5 \%$, this segment was represented by E. Coli, K. Pneumonia. As for E. Coli, in Israel this pathogen accounts for $20 \%$ of cases of EONS, and the problem of infections of the early neonatal period caused by Klebsiella pneumoniae is relevant in Poland [31, 32].

In $30 \%$ of cases, NS was fatal. The key risk factors for this outcome are known to be low gestational age and low birth weight [33]. Moreover, our data are consistent with studies emphasizing that multiple organ failure and septic shock are the most significant predictors of death in NS [34].

Study limitations. There were some limitations in this study. The study was conducted in a single center. Our observations may be less applicable to different institutions when compared with multicenter, prospective studies. Furthermore, there were sample size limitations. This could affect the limitation of microbiological characteristics.

A plan for further research includes the study of the diagnostic significance of modern markers of sepsis in preterm infants.

\section{Conclusions}

1. In our study, the incidence of early neonatal sepsis confirmed by a positive blood culture was $34 \%$.

2. The most common cause of EONS in premature babies is CoNS (47\%), and a low incidence of sepsis of group B Streptococcus (5.8 \%) has been established.

3. Among the clinical forms of early NS, the most frequent septicopyemic source of infection were the lungs, which is expressed in the high incidence ( $94 \%$ ) of X-ray pneumonia in the structure of EONS.

\section{Conflict of interest}

The authors declare there is no conflict of interest.

\section{References}

[1] Sharma, D., Farahbakhsh, N., Shastri, S., Sharma, P. (2017). Biomarkers for diagnosis of neonatal sepsis: a literature review. The Journal of Maternal-Fetal \& Neonatal Medicine, 31 (12), 1646-1659. doi: http://doi.org/10.1080/14767058.2017.1322060

[2] Puopolo, K. M., Benitz, W. E., Zaoutis, T. E. (2018). Management of Neonates Born at $\leq 34$ 6/7 Weeks' Gestation With Suspected or Proven Early-Onset Bacterial Sepsis. Pediatrics, 142 (6), e20182896. doi: http://doi.org/10.1542/peds.2018-2896 
[3] Belachew, A., Tewabe, T. (2020). Neonatal sepsis and its association with birth weight and gestational age among admitted neonates in Ethiopia: systematic review and meta-analysis. BMC Pediatrics, 20 (1), 55. doi: http://doi.org/10.1186/s12887-020-1949-x

[4] Cai, S., Thompson, D. K., Anderson, P. J., Yang, J. Y.-M. (2019). Short- and Long-Term Neurodevelopmental Outcomes of Very Preterm Infants with Neonatal Sepsis: A Systematic Review and Meta-Analysis. Children, 6 (12), 131. doi: http:// doi.org/10.3390/children6120131

[5] Zea-Vera, A., Ochoa, T. J. (2015). Challenges in the diagnosis and management of neonatal sepsis. Journal of Tropical Pediatrics, 61 (1), 1-13. doi: http://doi.org/10.1093/tropej/fmu079

[6] Schrag, S. J., Farley, M. M., Petit, S., Reingold, A., Weston, E. J., Pondo, T. et. al. (2016). Epidemiology of Invasive Early-Onset Neonatal Sepsis, 2005 to 2014. PEDIATRICS, 138 (6). doi: http://doi.org/10.1542/peds.2016-2013

[7] Fjalstad, J. W., Stensvold, H. J., Bergseng, H., Simonsen, G. S., Salvesen, B., Ronnestad, A. E., Klingenberg, C. (2016). Early-onset Sepsis and Antibiotic Exposure in Term Infants: A Nationwide Population-based Study in Norway. The Pediatric Infectious Disease Journal, 35 (1), 1-6. doi: http://doi.org/10.1097/inf.0000000000000906

[8] Braye, K., Foureur, M., de Waal, K., Jones, M., Putt, E., Ferguson, J. (2019). Epidemiology of neonatal early-onset sepsis in a geographically diverse Australian health district 2006-2016. PLOS ONE, 14 (4), e0214298. doi: http://doi.org/10.1371/journal. pone. 0214298

[9] Giannoni, E., Agyeman, P. K. A., Stocker, M., Posfay-Barbe, K. M., Heininger, U., Spycher, B. D. et. al. (2018). Neonatal Sepsis of Early Onset, and Hospital-Acquired and Community-Acquired Late Onset: A Prospective Population-Based Cohort Study. The Journal of Pediatrics, 201, 106-114. doi: http://doi.org/10.1016/j.jpeds.2018.05.048

[10] Anderson-Berry, A., Bellig, L., Ohning, B. (2015). Neonatal sepsis: MedlinePlus Medical Encyclopedia. Available at: https:// medlineplus.gov/ency/article/007303.htm

[11] Wynn, J. L. (2016). Defining neonatal sepsis. Current Opinion in Pediatrics, 28 (2), 135-140. doi: http://doi.org/10.1097/ mop.0000000000000315

[12] Wynn, J. L., Polin, R. A. (2017). Progress in the management of neonatal sepsis: the importance of a consensus definition. Pediatric Research, 83 (1), 13-15. doi: http://doi.org/10.1038/pr.2017.224

[13] Wojkowska-Mach, J., Chmielarczyk, A., Strus, M., Lauterbach, R., Heczko, P. (2019). Neonate Bloodstream Infections in Organization for Economic Cooperation and Development Countries: An Update on Epidemiology and Prevention. Journal of Clinical Medicine, 8 (10). doi: http://doi.org/10.3390/jcm8101750

[14] Huggard, D., Powell, J., Kirkham, C., Power, L., O'Connell, N. H., Philip, R. K. (2019). Time to positivity (TTP) of neonatal blood cultures: a trend analysis over a decade from Ireland. The Journal of Maternal-Fetal \& Neonatal Medicine, 1-7. doi: http://doi.org/10.1080/14767058.2019.1617687

[15] Dillenseger, L., Langlet, C., Iacobelli, S., Lavaux, T., Ratomponirina, C., Labenne, M., Kuhn, P. (2018). Early Inflammatory Markers for the Diagnosis of Late-Onset Sepsis in Neonates: The Nosodiag Study. Front Pediatr, 6, 346. doi: http:// doi.org/10.3389/fped.2018.00346

[16] Wynn, J. L., Wong, H. R., Shanley, T. P., Bizzarro, M. J., Saiman, L., Polin, R. A. (2014). Time for a Neonatal-Specific Consensus Definition for Sepsis. Pediatric Critical Care Medicine, 15 (6), 523-528. doi: http://doi.org/10.1097/pcc.0000000000000157

[17] Klingenberg, C., Kornelisse, R. F., Buonocore, G., Maier, R. F., Stocker, M. (2018). Culture-Negative Early-Onset Neonatal Sepsis - At the Crossroad Between Efficient Sepsis Care and Antimicrobial Stewardship. Front Pediatr, 6, 285. doi: http:// doi.org/10.3389/fped.2018.00285

[18] Lacaze-Masmonteil, T., Rosychuk, R. J., Robinson, J. L. (2013). Value of a single C-reactive protein measurement at $18 \mathrm{~h}$ of age. Archives of Disease in Childhood - Fetal and Neonatal Edition, 99 (1), F76-F79. doi: http://doi.org/10.1136/archdischild-2013-303984

[19] Fjalstad, J. W., Stensvold, H. J., Bergseng, H., Simonsen, G. S., Salvesen, B., Ronnestad, A. E., Klingenberg, C. (2016). Early-onset Sepsis and Antibiotic Exposure in Term Infants: A Nationwide Population-based Study in Norway. The Pediatric Infectious Disease Journal, 35 (1), 1-6. doi: http://doi.org/10.1097/inf.0000000000000906

[20] Cantey, J. B., Wozniak, P. S., Pruszynski, J. E., Sánchez, P. J. (2016). Reducing unnecessary antibiotic use in the neonatal intensive care unit (SCOUT): a prospective interrupted time-series study. The Lancet Infectious Diseases, 16 (10), $1178-1184$. doi: http://doi.org/10.1016/s1473-3099(16)30205-5

[21] Ting, J. Y., Synnes, A., Roberts, A., Deshpandey, A., Dow, K., Yoon, E. W. (2016). Association Between Antibiotic Use and Neonatal Mortality and Morbidities in Very Low-Birth-Weight Infants Without Culture-Proven Sepsis or Necrotizing Enterocolitis. JAMA Pediatr, 170 (12), 1181-1187. doi: http://doi.org/10.1001/jamapediatrics.2016.2132

[22] Mohsen, L., Ramy, N., Saied, D., Akmal, D., Salama, N., Abdel Haleim, M. M., Aly, H. (2017). Emerging antimicrobial resistance in early and late-onset neonatal sepsis. Antimicrobial Resistance \& Infection Control, 6 (1). doi: http://doi.org/10.1186/ s13756-017-0225-9 
[23] Cotten, C. M. (2016). Adverse consequences of neonatal antibiotic exposure. Current Opinion in Pediatrics, 28 (2), $141-149$. doi: http://doi.org/10.1097/mop.0000000000000338

[24] Cailes, B., Kortsalioudaki, C., Buttery, J., Pattnayak, S., Greenough, A., Matthes, J. et. al. (2017). Epidemiology of UK neonatal infections: the neonIN infection surveillance network. Archives of Disease in Childhood - Fetal and Neonatal Edition, 103 (6), F547-F553. doi: http://doi.org/10.1136/archdischild-2017-313203

[25] Kuhn, P., Dheu, C., Bolender, C., Chognot, D., Keller, L., Demil, H., Astruc, D. (2010). Incidence and distribution of pathogens in early-onset neonatal sepsis in the era of antenatal antibiotics. Paediatr Perinat Epidemiol, 24 (5), 479-487. doi: http:// doi.org/10.1111/j.1365-3016.2010.01132.x

[26] Ohlin, A., Björkman, L., Serenius, F., Schollin, J., Källén, K. (2015). Sepsis as a risk factor for neonatal morbidity in extremely preterm infants. Acta Paediatrica, 104 (11), 1070-1076. doi: http://doi.org/10.1111/apa.13104

[27] Shin, Y.-J., Ki, M., Foxman, B. (2009). Epidemiology of neonatal sepsis in South Korea. Pediatrics International, 51 (2), 225-232. doi: http://doi.org/10.1111/j.1442-200x.2008.02685.x

[28] Drageset, M., Fjalstad, J. W., Mortensen, S., Klingenberg, C. (2017). Management of early-onset neonatal sepsis differs in the north and south of Scandinavia. Acta Paediatrica, 106 (3), 375-381. doi: http://doi.org/10.1111/apa.13698

[29] Leal, Y. A., Álvarez-Nemegyei, J., Velázquez, J. R., Rosado-Quiab, U., Diego-Rodríguez, N., Paz-Baeza, E., Dávila-Velázquez, J. (2012). Risk factors and prognosis for neonatal sepsis in southeastern Mexico: analysis of a four-year historic cohort follow-up. BMC Pregnancy and Childbirth, 12 (1). doi: http://doi.org/10.1186/1471-2393-12-48

[30] Ozkan, H., Cetinkaya, M., Koksal, N., Celebi, S., Hacımustafaoglu, M. (2014). Culture-proven neonatal sepsis in preterm infants in a neonatal intensive care unit over a 7 year period: Coagulase-negativeStaphylococcusas the predominant pathogen. Pediatrics International, 56 (1), 60-66. doi: http://doi.org/10.1111/ped.12218

[31] Klinger, G., Levy, I., Sirota, L., Boyko, V., Lerner-Geva, L., Reichman, B. (2010). Outcome of Early-Onset Sepsis in a National Cohort of Very Low Birth Weight Infants. PEDIATRICS, 125 (4), e736-e740. doi: http://doi.org/10.1542/peds.2009-2017

[32] Wójkowska-Mach, J., Borszewska-Kornacka, M., Domańska, J., Gadzinowski, J., Gulczyńska, E., Helwich, E. et. al. (2012). Early-onset Infections of Very-low-birth-weight Infants in Polish Neonatal Intensive Care Units. The Pediatric Infectious Disease Journal, 31 (7), 691-695. doi: http://doi.org/10.1097/inf.0b013e3182567b74

[33] Liang, L., Kotadia, N., English, L., Kissoon, N., Ansermino, J. M., Kabakyenga, J. et. al. (2018). Predictors of Mortality in Neonates and Infants Hospitalized With Sepsis or Serious Infections in Developing Countries: A Systematic Review. Frontiers in Pediatrics, 6. doi: http://doi.org/10.3389/fped.2018.00277

[34] Wen, L., Xu, L. (2020). The efficacy of dopamine versus epinephrine for pediatric or neonatal septic shock: a meta-analysis of randomized controlled studies. Italian Journal of Pediatrics, 46 (1). doi: http://doi.org/10.1186/s13052-019-0768-x 